\title{
James Chen annual award for best journal article
}

UMUAI is proud to announce that the following two articles have been elected as the recipients of the 2011 James Chen Annual Award for Best Journal Article (two awards were given out this year):

Evaluating and improving adaptive educational systems with learning curves Brent Martin, Antonija Mitrovic, Kenneth R. Koedinger and Santosh Mathan UMUAI 21:3, 2011, 249-28

An analysis of students' gaming behaviors in an intelligent tutoring system: predictors and impacts

Kasia Muldner, Winslow Burleson, Brett Van de Sande and Kurt VanLehn UMUAI 21:1-2, 2011, 99-135

The articles were selected based on nominations from journal reviewers, editorial board members and guest editors, and a subsequent comparative review of the shortlisted articles by an award committee.

The James Chen Annual Award for Best Journal Article has been donated by the Chen family in commemoration of James R. Chen, a creative researcher in the area of user modeling and information retrieval, and twice a UMUAI author. Each award carries a cash price of US\$1,000. 